\title{
OPTIMIZATION METHODS OF SUPPLY CHAIN MANAGEMENT
}

\section{PRAFULLA K SWAIN \& BIBHUTI B PRADHAN}

Department of Management, Siksha 'O'Anusandhan (Deemed to be University), Bhubaneswar, Odisha, India

\begin{abstract}
Supply network Management has expected a noteworthy job in company's exhibition and has pulled in genuine research consideration in the course of the most recent couple of years. Interconnected, interrelated or interlinked systems, channels and hub organizations join in the arrangement of items and administrations required by end clients in a supply network. Supply network the board has been characterized as the "structure, arranging, execution, control, and observing of inventory network exercises with the target of making net worth, fabricating a serious foundation, utilizing overall coordination's, synchronizing supply with request and estimating execution all around. Right now has been made to survey the writing on Supply Chain Management. A writing audit uncovers an extensive spurt in look into in principle and practice of SCM. A writing survey for 29 research papers for the period somewhere in the range of 2005 and 2011 has been introduced. The point of this examination was to give an exceptional and brief survey of the SCM writing that was centered around expansive zones of the SCM idea.

KEYWORDS: Optimization Methods, Supply Chain Management, Supply Chain Key Performance, Supply Network Management
\end{abstract}

Received: Jun 06, 2020; Accepted: Jun 26, 2020; Published: Aug 26, 2020; Paper Id.: IJMPERDJUN2020894

\section{INTRODUCTION}

In the ebb and flow serious situation supply network the executives accept a huge significance and calls for genuine research consideration, as organizations are tested with discovering approaches to meet ever-rising client desires at a sensible expense. To do as such, organizations must hunt out which parts of their supply network process are not serious, comprehend which client needs are not being met, set up progress objectives, and quickly actualize vital upgrades. Beforehand makers were the drivers of the supply network - dealing with the pace at which items were produced and disseminated. Today, clients are making major decisions, and makers are scrambling to satisfy client needs for alternatives/styles/highlights, snappy request satisfaction, and quick conveyance.

Practically speaking, inventory network based organizations (e.g., Dell, Wal-Mart, Samsung, Toyota, Lenovo, Gome, and so on.) have utilized diverse execution the executive's instruments to help their production network techniques. Checking and improvement of execution of a production network has become an undeniably perplexing assignment. An intricate exhibition the board system incorporates numerous administration forms, for example, recognizing measures, characterizing targets, arranging, correspondence, observing, detailing and criticism.

Assembling quality - a long-term serious differentiator - is moving toward equality no matter how you look at it, so satisfying customer's explicit needs for item conveyance has risen as the following basic open door for upper hand. Organizations that figure out how to improve the executives of their production network will turn 
into the new examples of overcoming adversity in the worldwide commercial center. Study on Benchmarking shows noteworthy cost contrasts between associations that display top tier execution and customarily, Supply Chain Management (SCM) has been a mixture of different angles, with impacts from coordination's and transportation, activities the board and materials and dissemination the executives, promoting, just as buying and data innovation (IT). In a perfect world, the sweeping way of thinking of SCM grasps every one of these capacities to deliver a general inventory network system that eventually upgrades firm execution.

This paper is meant to make a writing audit dependent on 29 arbitrarily picked inquire about papers on inventory network the executives where each exploration covers various items and highlights of production network the board. There is too modest quantity of research papers to be evaluated, that's why there is no goal to make any suggestions on inventory network the board execution or improvement, the main reason for existing is to make general audit dependent on these examination works which have been finished during the years from 2005 to 2011[1].

\section{Supply Chain Management Concept Definition}

Before making survey of picked papers there is a need to make a little conversation on meaning of supply network the executives itself.

SCM has been deciphered by different scientists. In light of the generally ongoing advancement of the supply network writing, it can't that there has been a lot of discussion as to a particular SCM definition. Ganesh an and Harrison has characterized SCM as a system of offices and dissemination choices that plays out the elements of acquisition of materials, change of these materials into moderate and completed items, and the circulation of these completed items to clients. Lee and Corey expressed that SCM comprises of the incorporation exercises occurring among a system of offices that get crude material, change them into transitional merchandise and afterward last items, and convey items to clients through a dissemination system. Christopher characterized the inventory network as the system of associations that are included, through upstream and downstream linkages, in the various procedures and exercises that produce an incentive as items and administrations in the hands of a definitive client. SCM is the "vital and deliberate coordination of the conventional business capacities and the strategies over these business capacities inside a specific firm and across organizations inside a supply network, for the motivations behind improving the long haul execution of the individual organizations and the inventory network all in all".

While the division of inventory network exercises among various organizations empowers specialization and economies of scale, there are numerous significant issues and issues that should be settled for fruitful production network activity - this is the primary motivation behind SCM[2], [3].

\section{Best Value Supply Chains}

The vast majority of inquires about are mean to discover ideal answers for tasks the executives in today's serious scene and best worth stockpile chains are the chains that are destined to flourish inside this today's rivalry.

Best worth stock chains utilize key production network the executives with an end goal to exceed expectations regarding speed, quality, cost, and adaptability. Regardless of the estimation of this idea to present day firms, little is thought about how conspicuous speculations can assist shed with lighting on what recognizes these chains from others and makes them astoundingly effective. 
Kitchen et al. noticed that as a generally new idea, the thought of best worth stockpile chains can become clearer and more extravagant whenever analyzed from an assortment of significant hypothetical points of view. Creators indicated suggestions for the best worth supply network idea offered by nine conspicuous hypothetical viewpoints: exchange cost financial matters, organization hypothesis, asset reliance hypothesis, institutional hypothesis, game hypothesis, arrange hypothesis, social capital hypothesis, key decision, and the asset based view/information based view. On our own kin can say that before expounding on the nine hypotheses, express that various different speculations can likewise help clarify supply network wonders (e.g., conduct hypothesis of the firm, punctuated harmony, mechanical association, possibility hypothesis, transformative financial aspects, and populace environment) [4], [5].

An ongoing review done by Feller et. al. of the primary uses of the expression "esteem" in the financial matters, showcasing, system, and tasks fields demonstrates that the thought of a worth chain may really be a misnomer, albeit a broadly utilized one. As indicated by this examination, just assets move along the chain of linkages between firms - supplies going one way and cash going the other, while esteem is a powerful seen quality related with the advantages that happen at the different purposes of trade along the asset chain. As per this examination, esteem encompasses the development of assets - is perceptual - and accumulates to the two gatherings in an exchange, providers and clients. In this manner, esteem chains can be thought to work in the two bearings, with providers gathering an incentive from the money related assets, installment terms, dependability, and future request spread that their clients give, while clients get an incentive from the conveyed items and administrations (Table 1).

An ongoing study done by Feller et. al. of the primary utilizations of the expression "esteem" in the financial aspects, advertising, technique, and activities fields demonstrates that the idea of a worth chain may really be a misnomer, albeit a generally utilized one. As per this investigation, just assets move along the chain of linkages between firms - supplies going one way and cash going the other, while esteem is a magical seen quality related with the advantages that happen at the different purposes of trade along the asset chain. As indicated by this investigation, esteem encompasses the development of assets - is perceptual - and accumulates to the two gatherings in an exchange, providers and clients. In this way, esteem chains can be thought to work in the two bearings, with providers gathering an incentive from the monetary assets, installment terms, dependability, and future request spread that their clients give, while clients get an incentive from the conveyed items and administrations[6], [7]. 
Table 1

\section{Table 1. How Different Theoretical Perspectives Help to Distinguish Best Value and} Traditional Supply Chains

\begin{tabular}{|c|c|c|}
\hline $\begin{array}{l}\text { Theoretical } \\
\text { perspective }\end{array}$ & Best value supply chains & Traditional supply chains \\
\hline \multirow{2}{*}{$\begin{array}{l}\text { Transaction cost } \\
\text { economics }\end{array}$} & $\begin{array}{l}\text { Focus on total costs, not just transaction } \\
\text { costs, as the basis of "make or buy" } \\
\text { decisions. }\end{array}$ & $\begin{array}{l}\text { Focus on transaction costs as the basis } \\
\text { of "make or buy" decisions. }\end{array}$ \\
\hline & $\begin{array}{l}\text { Short term costs play a secondary role if the } \\
\text { potential for long term, trusting relationships } \\
\text { exists }\end{array}$ & $\begin{array}{l}\text { Opportunism undermines trust; short } \\
\text { term costs are a primary consideration }\end{array}$ \\
\hline Agency theory & $\begin{array}{l}\text { Use reward structures and cultural } \\
\text { competitiveness to align members' interests } \\
\text { Potential for opportunism minimized }\end{array}$ & $\begin{array}{l}\text { Interests of supply chain members only } \\
\text { partially aligned Strong potential for } \\
\text { opportunism }\end{array}$ \\
\hline $\begin{array}{l}\text { Resource dependence } \\
\text { theory }\end{array}$ & $\begin{array}{l}\text { Supply chain members recognize that } \\
\text { dependence can create forbearance and trust }\end{array}$ & $\begin{array}{l}\text { Each member tries to avoid becoming } \\
\text { dependent on others and tries to make } \\
\text { others dependent on it }\end{array}$ \\
\hline Institutional theory & $\begin{array}{l}\text { Use industry recipes and best practices to } \\
\text { inform, but not dictate, supply chain } \\
\text { management activities }\end{array}$ & $\begin{array}{l}\text { Rely heavily on industry recipes and } \\
\text { best practices to guide supply chain } \\
\text { management activities }\end{array}$ \\
\hline Game theory & $\begin{array}{l}\text { Mutual dependence and trust overcome } \\
\text { members' temptation to pursue self-serving } \\
\text { behavior }\end{array}$ & $\begin{array}{l}\text { Some members use free riding, hold up, } \\
\text { and leakage to benefit themselves and to } \\
\text { the detriment of the chain }\end{array}$ \\
\hline Network theory & $\begin{array}{l}\text { A blend of strong and weak ties that matches } \\
\text { supply chain needs is created in order to } \\
\text { maximize supply chain performance }\end{array}$ & $\begin{array}{l}\text { Strong and weak ties formed on a case- } \\
\text { by-case basis rather than strategically }\end{array}$ \\
\hline Social capital theory & $\begin{array}{l}\text { Shared goals, values, and experiences create } \\
\text { shared sensemaking and improved } \\
\text { performance }\end{array}$ & $\begin{array}{l}\text { Mix of shared and firm-level goals, } \\
\text { values, and experiences circumscribe } \\
\text { shared sensemaking and limit } \\
\text { performance }\end{array}$ \\
\hline Strategic choice & $\begin{array}{l}\text { Strategic decisions made with concern for the } \\
\text { chain as the primary driver. This "strategic } \\
\text { supply chain management" opens the door to } \\
\text { unique blended strategies that transcend the } \\
\text { firm }\end{array}$ & $\begin{array}{l}\text { Strategic decisions made with concem } \\
\text { for the firm as the primary driver. This } \\
\text { approach constrains firms to using a } \\
\text { generic strategy such as prospector or } \\
\text { low cost leader }\end{array}$ \\
\hline $\begin{array}{l}\text { Resource-based } \\
\text { view/knowledge based } \\
\text { view }\end{array}$ & $\begin{array}{l}\text { Assume that unique resources exist at the } \\
\text { supply chain level, and that supply chains can } \\
\text { be inimitable competitive weapons }\end{array}$ & $\begin{array}{l}\text { Assume that unique resources reside } \\
\text { within firms. Supply chain management } \\
\text { is thus a tool to complement these } \\
\text { resources }\end{array}$ \\
\hline
\end{tabular}




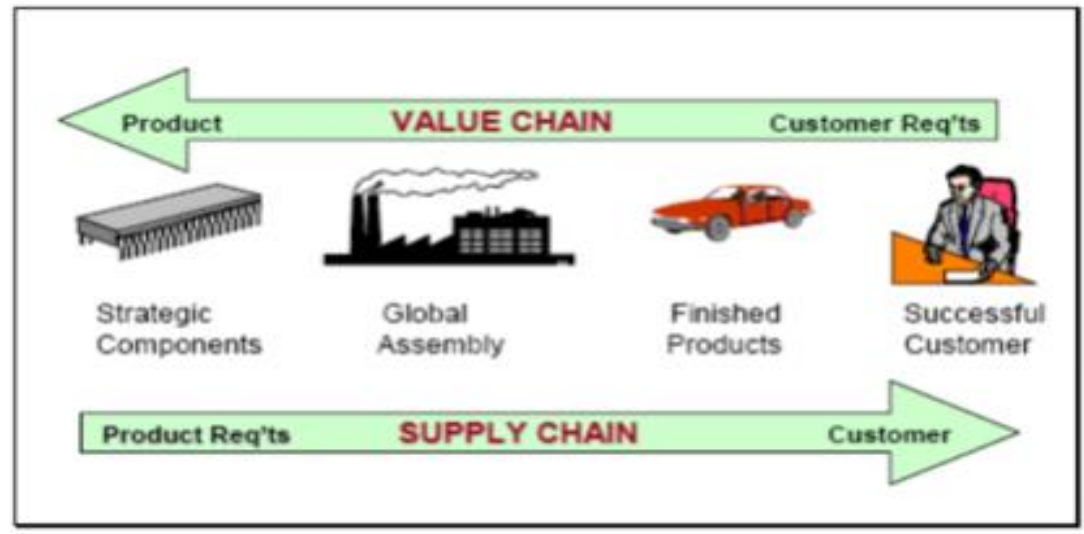

Figure 1. A Comparison of a Value Chain with a Supply Chain

Misnomer or not, the worth chain idea has become a staple thought in the administration and research writing, and is the concentration for advancing systems, endeavor models, and various endeavors at improving business execution. Making a gainful worth chain in this manner requires arrangement between what the client needs, i.e., the interest chain, and what is created by means of the supply network (Figure 1). And keeping in mind that supply chains center principally on diminishing expenses and accomplishing operational greatness, esteem chains center more around advancement in item improvement and advertising. Alongside of it there is inquire about in quality administration which has been finished by Foster has concentrated on inward versus outer perspectives on quality, with the inside view concentrating on process and the outside view concentrating on the client.

As firms receive the systems approach certain in production network the board, they should combine these perspectives as they disguise upstream and downstream procedures with their own. To comprehend the field of inventory network quality administration (SCQM), individuals should initially characterize the term by deconstructing it. Bowers ox et al. express that production network the board comprises of firms working together to use vital position and to improve working proficiency. This incorporates collaborating with different firms in chains of connections that bring about downstream advantages to clients. Likewise, the quality administration point of view has generally considered cooperating parts of systems, for example, forms, inputs, machines, individuals, methods, plant, and hardware as methods for making greatness in items and administrations.

This systems based perspective on quality applies to supply chains too. As indicated by Fawcett et al., rivalry currently can't found at the firm level. Business rivalry presently exists as supply fastens try to pick up advantage over contending supply chains. This degree of rivalry requires an a lot more prominent degree of coordination among chains or systems of providers, wholesalers, makers, and clients. Another issue is to keep supportability of supply chains. The idea of the errand of coordinating supportability in inventory network the board is unpredictable and will in general outcome in clashes. Besides, where clashes have emerged a goals structure in supply network the board investigate can't accessible. The underlying foundations of production network the board examine are comprehensively planted in tasks the executives and thusly the setting is activities and not the natural or social angles, and that has not changed as it is inalienable to the field. The idea of the undertaking and setting directly survive (or ,abduct ${ }^{\text {ee }}$ ) different components that may legitimize the inadvertent lingering of changing production network the board into maintainable supply network the executives. Abridging 
to incite an auxiliary change it is basic to consider the clashing idea of the undertaking and the setting of production network the executives investigate[6]-[10].

\section{Evaluation and Optimization Methods of SCM}

Still numerous strategies and procedures have been proposed throughout the years for SCM assessment. Conventional strategies center on notable monetary measures, for example, the arrival on venture (ROI), net present worth (NPV), the inside pace of return (IRR), and the restitution time frame. These strategies are most appropriate to gauge the estimation of basic SCM applications. Lamentably, assessment techniques that depend on money related measures are not appropriate for more up to date age of SCM applications. These mind boggling supply fastens ordinarily try to give a wide scope of advantages, remembering numerous that are elusive for nature. During conversation of strategies let's stop on a system which is a series of expectations about reason and effect. On the off chance that circumstances and logical results connections are not sufficiently reflected in the BSC, it won't interpret and convey firm's vision and methodology. These circumstances and logical results connections can include a few or every one of the four of the viewpoints in the BSC system. For instance, adaptability of administration systems to meet specific client needs (inside business activities point of view) will be bound to meet client desires (client viewpoint). More elevated level of client desires will lead organizations to supply increasingly inventive items and administrations (learning and development viewpoint).

This thus will build the piece of the pie and gainfulness (money related point of view). Additionally there is no uncertainty about the significance of educating in the supply network and about the way that data innovation (particularly different Internet applications) can significantly decrease the costs, vital arranging of this procedure and usage of data is pivotal. Data ought to be promptly accessible to all organizations in the supply network and the business procedures ought to be organized in a manner to utilize this data. The most significant proportions of SCM achievement can be the last degree of administration, consumer loyalty and supply network seriousness and gainfulness overall. Anyway as these are hard to gauge or use as a rule to screen improvement, progressively operational estimation techniques and lists were created. On an increasingly operational level the key execution markers are absolute costs, quality and lead times in the supply network. Overview of execution measures demonstrated that cost and client responsiveness command as the regularly referenced measures.

Cai et al from opposite side, proposes a structure utilizing a precise way to deal with improving the iterative key presentation pointers (KPIs) achievement in a supply network setting. The proposed look into quantitatively examines the reliant connections among a lot of KPIs. It can recognize critical KPI achievement costs and propose execution improvement procedures for leaders in a supply network. In that examination is given a compelling way to deal with overseeing inventory network execution in a powerful domain. It takes care of the presentation estimates coupling issue by utilizing a deliberate methodology, while not many of past research works have tended to this issue.

The structure and strategy assist organizations with improving execution over the whole inventory network in a deliberate way, through overseeing complex connections among the KPIs, and refining the way toward deciding their KPIs. From the structure, it is doable to get an all-encompassing perspective on complex connections among KPIs, where the reason impact graph turns out to be too convoluted on account of the huge number of KPIs. The system and approach offer at any rate three significant hypothetical commitments to take care of coupled KPI achievement issues and give a decent knowledge to additionally work. Which are as followings: first, the proposed structure gives a decent execution plan which 
changes over the mind boggling critical thinking into a progressively operational and quantitative exercise; second, the PCTM (achievement cost change network) investigation proposed in Caius paper is another augmentation of the current Eigen structure examination techniques (e.g., Work Transformation Matrix - WTM - got from the DSM model) from designing to business execution the board; third, the system and PCTM investigation strategy can fill in as a valuable demonstrating instrument in breaking down coupled improvement issues. Explores acknowledge that from PCTM ought not to be received as immediate choices, yet as supporting data for dynamic. Since various specialists may have various assessments of basic markers, and of various potential arrangements; each master or chief may have his own PCTM. There is no standard answer that can be acknowledged (and executed) consistently. Thus, Cain announces that an official conclusion making is still left to the supervisors.

Chow et al., made an attempt to break down SCM in examination of two unique nations US and Taiwan and to check whether techniques utilized for advancement can be equivalent for any condition. Through auxiliary condition displaying, basic parts of supply network the board are found to effect sly affect authoritative execution. The discoveries of Chow et al., are abridged as follows:

- Supply chain capabilities effect sly affect hierarchical execution in both the US and Taiwan. Production network skills are created around quality and administration, tasks and dissemination, and structure viability. The objective of production network abilities is to fulfill client prerequisites.

- Supply chain rehearses, which are comprised of production network highlights, combination, and client administrations, have direct effect on hierarchical execution in Taiwan, yet they have just aberrant effect in the US.

- Supply chain practices and skills are fundamentally related in both the US and Taiwan.

- In any case, supply network concerns and practices are related on account of the USA as it were. Study shows that the act of production network the executives might be fundamentally or circumstance subordinate. In this way, there might be various discernments from nation to nation on the most proficient method to viably deal with a supply network. Along these lines, it can't instance of "one size fits all." Each country's circumstance might be unique and would should be comprehended to successfully deal with the production network. The confirmations introduced right now the thought that compelling production network the executives would empower endeavors to get serious in the new economy and fundamentally improve their presentation. Inventory network ability has positive impact on authoritative execution. Administrators need to concentrate consideration on growing such capabilities. Carlson et. $\mathrm{Al}$, on his own made a very fascinating exploration on production network the executives on case of mash and paper industry. Creators infer that the mash and paper industry relies upon a long and incorporated inventory network.

The lead time from the initial step to the keep going is long and it includes numerous means worked by a few organizations and associations. They are progressively centered on arranging process which is one of noteworthy angles in chain the board. Arranging issues are isolated into vital, strategic and usable in a supply network lattice and depicted their attributes. They infer that the requirement for data and choice help for organizers in every one of these territories is noteworthy. This identifies with an arranging inside a solitary organization just as coordinated arranging over a few. While SCM considers are as a rule dependent on examines about assembling industry, there is some writing which audits production network the board inside the setting of the travel industry. Broad research by Zhang et al., has demonstrated that coordination 
among supply network accomplices in the beginning period of item advancement benefits the effective improvement of new items in the time of mass customization.

Late research additionally shows the benefits of enhancing the item configuration, process structure, and supply choices in a coordinated and synchronous way. Plainly the general execution estimation of a supply network system includes not simply budgetary or operational estimation. Given the intricacy of evaluating such an adaptable system, different systems have been proposed. As in other assistance enterprises, consumer loyalty (traveler fulfillment) is one of the most significant presentation measures for the travel industry inventory network. The travel industry specialists have explored the estimation of in general traveler fulfillment with a specific goal and vacationer fulfillment with explicit assistance areas, for example, convenience, eateries, attractions, travel organizations, bundle visits, and retail shops.

In today's serious condition, the sheer number of the travel industry administration providers gives rich info prospects to visit administrators to gather visit bundles, and it is accepted that compelling incorporation of providers with the travel industry item advancement procedures could build the serious edge of visit administrators just as advantage the TSC all in all.

\section{CONCLUSIONS}

Right now endeavor has been made to survey the writing on Supply Chain Management. A writing audit for 29 research papers for the period somewhere in the range of 2005 and 2011 has been introduced. Articles for survey were picked in irregular manner where a lone model for investigate papers was to be done after 2005. So as to have more extensive view on SCM, papers checked on which have various articles, were they are isolated into such gatherings: (1) papers which investigate SCM in setting of its improvement and quality, (2) papers which center around manageability of SC and coordination's, (3) papers which dependent on correlation of SCs or examination of executing strategies on various areas, (4) papers which look towards SCM through changed industry, (5) lastly the most significant number of inquiries about will be about techniques for supply and productivity of SCs. A writing survey uncovers an impressive spurt in look into in principle and practice of SCM. Joining and advising on highlights of Supply Management and conveyance Management. This incorporation has brought about the idea of expanded undertaking and the production network is presently show as the community oriented supply network across intercompany fringes to augment the incentive over the whole inventory network. As an ever increasing number of firms have high caliber and ongoing data accessible, the utilization of these choice advancements will increment, since they enhance the individuals from a supply network. The SCM is persistently rethinking itself. It has been seen that past writing surveys gave important outcomes, they depended on the irregular determination of articles, book parts and gathering procedures. Other writing surveys were either increasingly centered around tasks the board or inspected a solitary diary. The point of this investigation was to give a cutting-edge and brief audit of the SCM writing that was centered around wide regions of the SCM idea. It is our expectation that future explores will give more consideration on producing genuinely necessary reasonable and exact work in the SCM writing, in this manner making an assortment of writing that is all the more vigorously affected by a more profound examination of the supply network on a chain wide or organize premise.

\section{REFERENCES}

1. H. R. Lourenço and M. G. Ravetti, "Supply chain management," in Handbook of Heuristics, 2018.

2. Supply Chain Council, "Supply Chain Operations Reference Model - Overview," in Supply Chain Operations Management, 2012. 
3. S. Seuring, “A review of modeling approaches for sustainable supply chain management," in Decision Support Systems, 2013, doi: 10.1016/j.dss.2012.05.053.

4. B. Fahimnia, J. Sarkis, and H. Davarzani, “Green supply chain management: A review and bibliometric analysis, ”International Journal of Production Economics. 2015, doi: 10.1016/j.ijpe.2015.01.003.

5. D. M. Z. Islam, J. Fabian Meier, P. T. Aditjandra, T. H. Zunder, and G. Pace, "Logistics and supply chain management,” Res. Transp. Econ., 2013, doi: 10.1016/j.retrec.2012.10.006.

6. W. Ho, T. Zheng, H. Yildiz, and S. Talluri, "Supply chain risk management: A literature review," International Journal of Production Research. 2015, doi: 10.1080/00207543.2015.1030467.

7. J. Sarkis, Q. Zhu, and K. H. Lai, “An organizational theoretic review of green supply chain management literature," International Journal of Production Economics. 2011, doi: 10.1016/j.ijpe.2010.11.010.

8. P. J. Martínez-Jurado and J. Moyano-Fuentes, "Lean management, supply chain management and sustainability: A literature review," J. Clean. Prod., 2014, doi: 10.1016/j.jclepro.2013.09.042.

9. A. Rajeev, R. K. Pati, S. S. Padhi, and K. Govindan, "Evolution of sustainability in supply chain management: A literature review, "Journal of Cleaner Production. 2017, doi: 10.1016/j.jclepro.2017.05.026.

10. L. Lei, L. DeCandia, R. Oppenheim, and Y. Zhao, "Introduction to Supply Chain Management," in Managing Supply Chain Operations, 2017. 
